\title{
miR-30e targets GLIPR-2 to modulate diabetic nephropathy: in vitro and in vivo experiments
}

\author{
Dong Zhao', Jinhua Jia² and Hong Shao' \\ 'Department of Nephrology, Jining NO.1 People's Hospital, Jining, Shandong, People's Republic of China \\ 2Department of Nephrology, Ankang Hospital of Traditional Chinese Medicine, Ankang, Shaanxi, \\ People's Republic of China
}

Correspondence should be addressed to $\mathrm{H}$ Shao Email

shshsh0405@163.com

\begin{abstract}
The objectives of this study are to investigate the effect of miR-30e targeting GLIPR-2 on the pathological mechanism of DN. The renal tissues of $\mathrm{db} / \mathrm{db}$ and $\mathrm{db} / \mathrm{m}$ mice at different age of weeks were stained with PAS. qRT-PCR was applied to detect the expression of miR-30e and GLIPR-2, not only in the renal tissues of mice but also in the renal tubular epithelial cells (RTECs). By luciferase reporter gene assays, we found the $3^{\prime}$-UTR of the GLIPR-2 mRNA as a direct target of miR-30e. The RTECs cultured in high glucose were divided into blank control, NC, miR-30e mimics, miR-30e inhibitors,

miR-30e inhibitor + si-GLIPR-2 and si-GLIPR-2 groups. MTT and flow cytometry were utilized to measure the proliferation and apoptosis of RTECs, while qRT-PCR and Western blot to detect the expression of GLIPR-2- and EMT-related factors. The following results were obtained: In the renal tissues of over 8-week-old db/db mice and the RTECs cultured for $6 \mathrm{~h}$ in high glucose, miR-30e was downexpressed while GLIPR-2 was upregulated in a time-dependent manner. Besides, overexpression of miR-30e and si-GLIPR-2 can not only greatly improve the proliferation of RTECs cultured in high glucose, but also downregulate the apoptosis rate of RTECs and the expressions of GLIPR-2, vimentin, $\alpha$-SMA, Col-I and FN and upregulate E-cadherin. Moreover, si-GLIPR-2 can reverse the proliferation reduction, GLIPR-2 and EMT occurrence caused by the downexpression of miR-30e in RTECs. In conclusion, miR-30e is downregulated in DN, and the overexpression of miR-30e can inhibit GLIPR-2, promote the proliferation of RTECs and inhibit EMT, ultimately avoid leading to renal fibrosis in DN.
\end{abstract}

Journal of Molecular

Endocrinology

(2017) 59, 181-190

\section{Introduction}

Diabetic nephropathy (DN), as one of the most common complications of diabetes mellitus (DM), is known to be one of the important causes of renal failure (Wu et al. 2016). With the incidence increasing year by year, DN has become a hard nut for the public health around the world (Marshall 2014). According to the estimation of WTO, the population of diabetes patients worldwide will reach
370 million by 2025 and thirty percent of these patients will develop into DN (Kainz et al. 2015). Generally, the distinctive pathological changes of DN include mesangial cell proliferation, mesangial widening and abnormal accumulation of extracellular matrix (ECM), which will result in glomerular sclerosis (GS) and tubulointerstitial fibrosis (TIF) and eventually cause chronic renal failure, 
reducing patients' quality of life and endangering patients' lives (Brosius et al. 2010, Shields \& Maxwell 2010). At present, traditional therapies to control blood glucose and blood pressure, or to block the renin-angiotensin system (RAS) can delay the progression of DN, but still no effective treatment is available to prevent or reverse the progression from DN to renal function failure (Chung 2015). Therefore, it becomes really important and urgent to explore the pathogenesis of DN in depth and recognize a new target for DN treatment, which provides new insight for the clinical prevention and treatment of DN.

MicroRNA (miRNA), a family of small non-coding endogenous RNA (containing about 22 nucleotides), can identify the $3^{\prime}$ untranslated region (3'-UTR) of its target gene by means of base pairing, and thus inducing the degradation of target mRNA and inhibiting the translation of proteins (Zhang et al. 2015). Besides, miRNA plays an important part in many different physiological and pathological processes, including the growth and differentiation of organism, cell proliferation and tumor, inflammation and endocrine diseases (Jackson \& Levin 2012). To date, a great number of studies have found miRNAs to be involved in the development and progression of DN (Kato \& Natarajan 2012, Simpson et al. 2016). For instance, miR-216a (Kato et al. 2010), miR-200a (Wang et al. 2011), miR-29c (Long et al. 2011) and miR-25 (Fu et al. 2010) can affect the synthesis of ECM protein in mesangial cells and the renal tubular epithelial-mesenchymal transition (EMT) by regulating their target genes, which will lead to the excessive accumulation of ECM and induce GS and TIF. Therefore, it is hypothesized that these miRNAs can greatly affect the pathogenesis and development of DN. Additionally, Joglekar and coworkers found that miR-30 family can also regulate EMT in cultured human pancreatic islet cells in vitro (Joglekar et al. 2009b). For example, it has been proved that miR-30c can target CTGF and Snail1 to inhibit TGF- $\beta 1$-induced EMT of renal tubular epithelial cells (RTECs) (NRK-52E) (Zheng et al. 2016), while miR-30e can target UCP2 to reduce the production of TGF- $\beta 1$-induced ECM in tubular epithelial cells, so as to alleviate renal fibrosis (Jiang et al. 2013).

GLIPR-2 belongs to the superfamily of CAP proteins and is also a kind of Golgi membrane protein (Gibbs et al. 2008). Baxter and coworkers reported that the expression of GLIPR-2 went up remarkably in the glomerulus of DN patients, which may induce the EMT of RTECs and accelerate renal pathological changes (Baxter et al. 2007). With target gene prediction software, we found that GLIPR-2 is a direct target of miR-30e. However, it has rarely been studied about whether miR-30e is involved in TIF by targeting GLIPR-2 of DN patients. Therefore, this study explored the association of DN with miR-30e and GLIPR-2 to understand the pathological mechanism of DN from a new perspective and provide new targets for the early diagnosis, treatment and intervention of DN.

\section{Materials and methods}

\section{Ethics statement}

This study was approved by the Ethics Committee of Jining NO.1 People's Hospital. All animals were raised and treated in accordance with the Guide for the Care and Use of Laboratory Animals (Carbone 2012) by National Institutes of Health of the USA.

\section{Establishment and grouping of DM animal models}

Thirty-two 4-week-old male C57BL/KsJ db/db mice with type II DM and another $32 \mathrm{db} / \mathrm{m}$ mice of the same age were included in the experiment. All mice were purchased from the Model Animal Research Center of Nanjing University. When these mice were at the age of 4-, 8-, 12and 16-week-old, urine of $24 \mathrm{~h}$ and blood specimens were collected from them (with 8 mice at each time point). Then, Thshiba-120FR automatic biochemical analyzer (Toshiba Corporation, Tokyo, Japan) was used to detect the 24-h urinary albumin excretion (UAE), blood glucose (Glu) changes, serum creatinine (Scr) level and blood urea nitrogen (BUN) level. Before the mice were killed, they were fasted for $12 \mathrm{~h}$, measured for body weight (BW) and given $2 \%$ pentobarbital sodium $(40 \mathrm{mg} / \mathrm{kg}$ ) by intraperitoneal injection. Then, bilateral kidneys were taken after laparotomy and connective tissues like blood vessels on the renal hilum were removed. Next, the renal tissues of one kidney were fixed in 10\% neutral formalin, embedded in paraffin and sliced into $2-\mu \mathrm{m}$ sections. Then, the tissue sections were given periodic acid-Schiff (PAS) staining and observed under the light microscope to find out the pathological changes in renal tissues. At the same time, the renal tissues of the other kidney were preserved in liquid nitrogen for RNA extraction.

\section{Diagnosis of DM in model mice}

The diagnosis of nephropathy in diabetic animal models was based on the diagnostic criteria recommended by the Animal Models of Diabetic Complications Consortium (AMDCC) (Brosius et al. 2009). Compared with mice of

Published by Bioscientifica Ltd. 
the same sex and age in the control group, $\mathrm{db} / \mathrm{db}$ mice in the DM group was over 100 times higher in proteinuria and over 50\% lower in G-protein-coupled receptors (GPR). Besides, db/db mice in the DM group of our study showed renal pathological features, including GS, TIF, renal arteriolar hyalinization and over 50\% thickening of glomerular basement membranes (GBM).

\section{High-glucose-stimulated renal tubular epithelial cell model}

The mouse RTECs were purchased from the Cell Bank of Chinese Academy of Sciences. The RTECs were cultured in the medium with glucose concentration of $30 \mathrm{mmol} / \mathrm{L}$ (DN group), and glucose concentration of $5.6 \mathrm{mmol} / \mathrm{L}$ (control group) were cultured with. Related indexes were determined after the cells were cultured for 6, 12, 24 and $48 \mathrm{~h}$ respectively.

\section{Dual-luciferase reporter gene assay}

The target gene analysis of miR-30e was conducted in the biological prediction website, microRNA.org, and GLIPR-2 was confirmed to be a direct target gene of miR-30e. Together with TK (thymidine kinase-Renilla reniformis luciferase plasmid) as the internal reference plasmid (by $10 \mathrm{ng} /$ well), the plasmid pcDNA3.1-miR-30e used for the overexpression of miR-30e or the empty plasmid pcDNA3.1 used as control was transfected into RTECs (by $50 \mathrm{ng} /$ well). Lipo2000 was selected as the transfection reagent. About $8 \mathrm{~h}$ after transfection, the cells were cultured for another 36h in Dulbecco's Modified Eagle's Medium (DMEM) containing 5\% fetal bovine serum (FBS) before being collected to wash three times with phosphate buffered saline (PBS). Then, $50 \mu \mathrm{L}$ of passive lysis buffer was added into each well before shaking the culture dish for $15 \mathrm{~min}$ at room temperature. The luciferase activity of GLIPR-2 was tested by Dual-Luciferase Reporter Assay System Kit (Promega). Before the activity detection, $10 \mu \mathrm{L}$ of cell lysate was taken and transferred into white 96-well plate. Moreover, the luciferase activity of reporter gene was measured by Luciferase Assay Reagent II. Stop\&Glo Reagent was used to activate the fluorescence signal of TK, and the luciferase activity ratio of reporter gene to TK was the desired result.

\section{Cell transfection and grouping}

RTECs cultured in high glucose were divided into the following 6 groups: Mock group (transfected with no sequences), NC group (transfected with the negative control sequence of miR-30e, purchased from Shanghai GenePharma Co., Ltd.), miR-30e mimics group (transfected with miR-30e mimics, purchased from Shanghai GenePharma Co., Ltd.), miR-30e inhibitors group (transfected with miR-30e inhibitors, purchased from Shanghai GenePharma Co., Ltd.), miR-30e inhibitor +si-GLIPR-2 group (transient transfection with miR-30e inhibitors + transfection with GLIPR-2 siRNA) and si-GLIPR-2 group (transfected with GLIPR-2 siRNA). The day before transfection, we obtained high-glucoseexposed RTECs that are at the logarithmic phase and inoculated them into the 6-well plate with $10^{5}-10^{6}$ cells in each well. Next day, transfection was performed by following the instructions for Lipofectamine2000 (Invitrogen).

\section{MTT assay detects the proliferation of high-glucose- stimulated renal tubular epithelial cells}

RTECs obtained in the logarithmic growth phase were seeded into the 96 -well plate by $1 \times 10^{4}$ cells/well. After adhering to the plate wall, the cells were cultured in $\mathrm{CO}_{2}$ incubator at $37 \mathrm{C}$, and the cell proliferation was detected at the time points of $24,48,72$ and $96 \mathrm{~h}$. Then, $20 \mu \mathrm{L}$ of $5 \mathrm{mg} / \mathrm{mL}$ MTT was added to each well, cells were cultured for another $4 \mathrm{~h}$ at $37 \mathrm{C}$ and the supernatant was removed. Next, after adding $150 \mu \mathrm{L}$ of DMSO into each well, the plate was oscillated for $10 \mathrm{~min}$ for the full dissolution of the crystallization. The Microplate reader was utilized to detect the absorbance value (also called optical density, OD) of each well under the wavelength of $490 \mathrm{~nm}$, and the blank tube was set as zero. The experiment would be repeated for 3 times and the OD value considered representing the proliferation activity of cells.

\section{Flow cytometry detects the apoptosis of high-glucose- stimulated renal tubular epithelial cells}

The RTECs in different transfected groups were washed with ice-cold PBS (4C) for 2 times, and then re-suspended in $1 \times$ binding buffer, resulting in the final concentration of $1 \times 10^{6}$ cell $/ \mathrm{mL}$. Then, $100 \mu \mathrm{L}$ of suspension, $5 \mu \mathrm{L}$ of Annexin V-FITC and $5 \mu \mathrm{L}$ of propidium iodide (PI) were added into labeled Falcon tubes and incubated for $15 \mathrm{~min}$ at room temperature. Finally, $400 \mu \mathrm{L}$ of binding buffer was added and then detected by using flow cytometry (BD). http://jme.endocrinology-journals.org DOI: 10.1530/JME-17-0083
() 2017 Society for Endocrinology Printed in Great Britain
Published by Bioscientifica Ltd 
qRT-PCR detects the expression levels of miR-30e-, GLIPR-2- and EMT-related factors

The extraction process of total RNA was aligned with the instructions of TRIzol Reagent (Invitrogen) and qRT-PCR was performed in accordance with the instructions of TaKaRa SYBR Prime Script miRNA RT-PCR Kit. In addition, U6 sn RNA was the internal reference gene for miR-30e and GAPDH the internal reference for GLIPR-2, Vimentin, $\alpha$-SMA, Col-I, FN and E-cadherin. And all primers were purchased form Guangzhou RiboBio Co., Ltd. (Guangzhou, China). The relative expression was calculated by using $2-\Delta \Delta \mathrm{Ct}$ to present the gene expression ratio of the experiment group to the control group. The calculation formula is as follows: $\quad \Delta \Delta \mathrm{CT}=\Delta \mathrm{Ct} \mathrm{t}_{\text {experiment }}$ group $-\Delta \mathrm{Ct}$ control group' and $\Delta \mathrm{Ct}=\mathrm{Ct}_{\text {target gene }}-\mathrm{Ct}_{\mathrm{U} 6}$.

\section{Western blot detects the expression of GLIPR-2 and EMT-related proteins}

Cells cultured for $24 \mathrm{~h}$ were collected from each group before adding pre-cooled RIPA lysis solution. The homogenate was transferred into a centrifuge tube for $10 \mathrm{~min}$ of $7500 \mathrm{~g}$ centrifugation at $4^{\circ} \mathrm{C}$. Then, the supernatant was obtained for dilution and protein quantitation. In other words, loading buffer was used to adjust the concentration and volume of cell proteins, and $20 \mu \mathrm{L}$ samples were given electrophoresis with $70 \mathrm{~V}$ of electric voltage in $12 \%$ polyacrylamide gel. After the electrophoresis, cell proteins were transferred to the membrane and closed for $1 \mathrm{~h}$ at room temperature on de-colorization oscillator with TBS-T containing 5\% BSA. Then, the closure solution was discarded, the membrane was placed into a plastic groove and the primary antibodies were added for overnight reaction at $4 \mathrm{C}$, including anti-GLIPR-2 (1:100, ab122059, Abcam), antiVimentin (1:1000, ab92547, Abcam), anti- $\alpha$-SMA (1:1000, ab108424, Abcam), anti-Col-I (1:1000, ab34710, Abcam), anti-FN $(1 \mu \mathrm{g} / \mathrm{mL}$, ab23750, Abcam), anti-E-cadherin (1:1000, ab76055, Abcam) and anti-GAPDH (1:1000, ab8245, Abcam). Next day, the membrane was rinsed for three times with TBS-T for $10 \mathrm{~min}$ each time. In the same way, diluted secondary antibodies (Abcam) were added for $1 \mathrm{~h}$ of shaking incubation at room temperature. Then, the membrane was washed with TBS-T for $15 \mathrm{~min} \times$ three times. A solution and B solution in the Chemiluminescence Reagent Kit (Vazyme Biotech Co., Ltd., Nanjing, China) were mixed (1:1) and dropped onto the nitrocellulose membrane for developing. All immunoblot bands were analyzed using the software ImageJ.

\section{Statistical analysis}

The data were analyzed with the software SPSS 21.0. Measurement data in our study was presented by mean \pm S.D. $( \pm s)$. The difference between two groups was analyzed by using $t$-test and the comparison among multiple groups was analyzed by one-way ANOVA. $P<0.05$ was considered to be with statistical difference.

\section{Results}

The changes in the general status and biochemical index of $\mathrm{db} / \mathrm{db}$ mice in DM group

The $\mathrm{db} / \mathrm{m}$ mice showed good growth status, normal diet, alert and active response and shining bright hair. However, with the increase of age, $\mathrm{db} / \mathrm{db}$ mice gradually showed symptoms of diabetes including polyphagia, polyuria and polydipsia. Besides, their BW increased significantly, their hair was fluffy and gray and they become lazy and dull in responses.

We observed the biochemical indexes of mice at different time points and found that at the age of 4-week, $\mathrm{db} / \mathrm{db}$ mice become fat and showed obvious increase in BW when compared with $\mathrm{db} / \mathrm{m}$ mice $(P<0.05)$, but no significant difference was found in Glu, Scr, BUN and UAE (all $P>0.05$ ). At the age of 8 -week, $\mathrm{db} / \mathrm{db}$ mice were statistically elevated in BW, Glu, Scr, BUN and UAE (all $P<0.05$ ), which can prove the occurrence of proteinuria and DN. Thereafter, with the age increase, $\mathrm{db} / \mathrm{db}$ mice showed further increase in BW, Glu, Scr, BUN and UAE (all $P<0.05$ ), which suggests the progression of $\mathrm{DN}$ in $\mathrm{db} / \mathrm{db}$ mice with the increase of age (Table 1 ).

\section{Pathological changes of renal tissues in mice}

Compared with $\mathrm{db} / \mathrm{m}$ mice, $\mathrm{db} / \mathrm{db}$ mice showed no obvious abnormality in renal tissues at 4 weeks; but showed glomerular swelling and hypertrophy at 8 weeks; obvious proliferation of glomerular mesangial cells at 12 weeks and typical DN pathological changes at 16 weeks, including hyperplasia and sclerosis of glomerular mesangial matrix and $\mathrm{K}-\mathrm{W}$ nodules. However, there was no evident change in renal tissues of $\mathrm{db} / \mathrm{m}$ mice at different age of weeks. These results indicated that 8 -week-old http://jme.endocrinology-journals.org DOI: 10.1530/JME-17-0083
(C) 2017 Society for Endocrinology Printed in Great Britain
Published by Bioscientifica Ltd 
Table 1 Dynamic evaluation and comparison of BW and blood urine biochemical indexes in two groups of mice.

\begin{tabular}{|c|c|c|c|}
\hline Time (W) & Groups & BW (g) & Glu (mmol/L) \\
\hline \multirow[t]{2}{*}{4} & $\mathrm{db} / \mathrm{m}$ & $13.24 \pm 0.85$ & $6.08 \pm 1.36$ \\
\hline & $\mathrm{db} / \mathrm{db}$ & $16.26 \pm 1.11$ * & $7.97 \pm 1.88$ \\
\hline \multirow[t]{2}{*}{8} & $\mathrm{db} / \mathrm{m}$ & $17.74 \pm 1.17$ & $5.96 \pm 1.51$ \\
\hline & $\mathrm{db} / \mathrm{db}$ & $39.29 \pm 1.70 * \#$ & $13.33 \pm 2.87^{* \#}$ \\
\hline \multirow[t]{2}{*}{12} & $\mathrm{db} / \mathrm{m}$ & $21.45 \pm 1.67$ & $5.99 \pm 1.85$ \\
\hline & $\mathrm{db} / \mathrm{db}$ & $43.19 \pm 1.20$ *\#\& & $20.13 \pm 2.28^{\star \# \& \&}$ \\
\hline \multirow[t]{2}{*}{16} & $\mathrm{db} / \mathrm{m}$ & $26.38 \pm 0.56$ & $7.32 \pm 2.00$ \\
\hline & $\mathrm{db} / \mathrm{db}$ & $53.97 \pm 1.83 * \# \& @$ & $24.88 \pm 2.04$ *\#\&@ \\
\hline
\end{tabular}

\begin{tabular}{l}
\multicolumn{1}{c}{$\mathbf{S c r}(\mu \mathrm{mol} / \mathrm{L})$} \\
\hline $14.83 \pm 2.30$ \\
$15.36 \pm 1.83$ \\
$16.83 \pm 1.76$ \\
$31.21 \pm 1.89 * \#$ \\
$17.22 \pm 2.49$ \\
$40.00 \pm 1.79 * \# \&$ \\
$17.94 \pm 3.01$ \\
$47.06 \pm 1.82^{* \# \& @}$ \\
\hline
\end{tabular}

\begin{tabular}{c}
\hline BUN (mmol/L) \\
\hline $6.65 \pm 0.29$ \\
$6.46 \pm 0.94$ \\
$5.84 \pm 0.51$ \\
$8.90 \pm 1.72 * \#$ \\
$6.28 \pm 0.91$ \\
$10.94 \pm 1.39$ *\#\& \\
$8.05 \pm 0.61$ \\
$12.28 \pm 0.95^{* \# \& @}$ \\
\hline
\end{tabular}

\begin{tabular}{|c|}
\hline UAE $(\mu \mathrm{g} / 24 \mathrm{~h})$ \\
\hline $12.29 \pm 1.49$ \\
\hline $13.87 \pm 2.16$ \\
\hline $13.02 \pm 2.66$ \\
\hline $131.17 \pm 0.28^{* \#}$ \\
\hline $14.57 \pm 1.88$ \\
\hline $216.00 \pm 5.20^{* \# \&}$ \\
\hline $15.02 \pm 1.31$ \\
\hline $265.52 \pm 5.95^{\star \# \& @ ~}$ \\
\hline
\end{tabular}

${ }^{*} P<0.05$ compared with $\mathrm{db} / \mathrm{m}$ mice of the same age; ${ }^{\# P}<0.05$ compared with 4-week-old $\mathrm{db} / \mathrm{db}$ mice; $\& P<0.05$ compared with 8 -week-old $\mathrm{db} / \mathrm{db}$ mice; $@ P<0.05$ compared with 12 -week-old db/db mice.

$\mathrm{db} / \mathrm{db}$ mice were at the early stage of $\mathrm{DN}$, and the severity of DN was correlated with age (Fig. 1).

\section{Expression of miR-30e and GLIPR-2 in the renal tissues and high-glucose-stimulated RTECs}

The results of qRT-PCR showed that 4-week-old $\mathrm{db} / \mathrm{db}$ mice had slightly lower expression of miR-30e and slightly higher expression of GLIPR-2 than $\mathrm{db} / \mathrm{m}$ mice of the same age (both $P>0.05$ ). However, 8-week-old $\mathrm{db} / \mathrm{db}$ mice showed significant reduction of miR-30e expression and obvious upregulation of GLIPR-2 expression when compared with $\mathrm{db} / \mathrm{m}$ mice of the same age (both $P<0.05$ ). In addition, with the increase of age, the miR-30e expression in renal tissues of $\mathrm{db} / \mathrm{db}$ mice continued to decrease while the GLIPR-2 expression kept increase in a time-dependent manner (all $P<0.05$ ). On the other side, the miR-30e and GLIPR-2 expression levels of $\mathrm{db} / \mathrm{m}$ mice showed no obvious change at different time points.

Compared with the control group, the miR-30e expression was significantly decreased and the GLIPR-2 expression was significantly increased in the RTECs of DN group cultured for $6 \mathrm{~h}$ in high glucose (both $P<0.05$ ).
Meanwhile, the changes were progressing with the prolonging high glucose exposure time, and after $48 \mathrm{~h}$ of high glucose exposure, the miR-30e expression decreased to the lowest level while the expression of GLIPR-2 reached the highest level (all $P<0.05$, Fig. 2).

\section{Detection of target relationship between miR-30e and GLIPR-2}

The biological prediction website microRNA.org showed that miR-30e was able to target GLIPR-2, so we conduct dual-luciferase reporter gene assay to verify this finding. Two types of fluorescence reporter vectors were constructed, namely, the mutant type GLIPR-2 3'UTR (MUT) with the deletion of miR-30e-binding site and the wild-type GLIPR-2 3'UTR (WT). According to the result analysis, transfection with miR-30e mimics had no obvious impact on mutant type GLIPR-2 3'UTR (MUT) $(P>0.05)$, but can lead to the significant reduction of luciferase signal intensity in wild-type GLIPR-2 3'UTR (WT) reporter gene vector $(P<0.05$, Fig. 3$)$. Therefore, it has been proved that GLIPR-2 is the direct target gene of miR-30e.

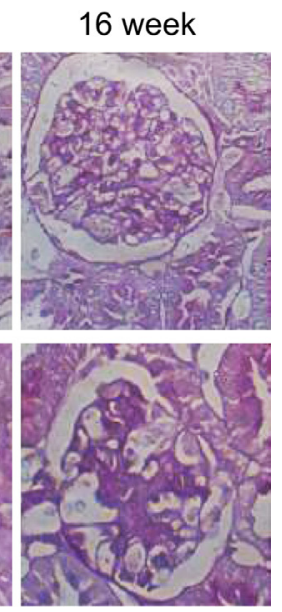

Figure 1

PAS staining of renal tissues in two groups of mice $(\times 400)$ http://jme.endocrinology-journals.org
DOI: 10.1530/JME-17-0083

(c) 2017 Society for Endocrinology Printed in Great Britain 
A

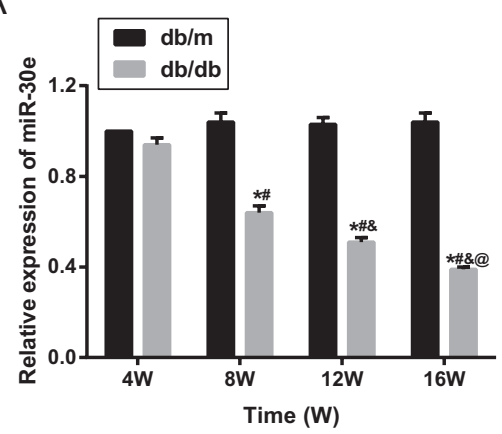

C

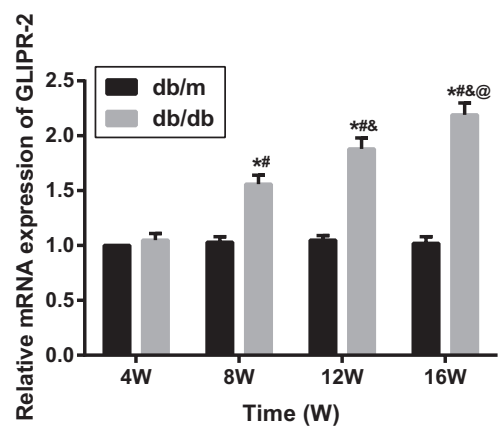

B

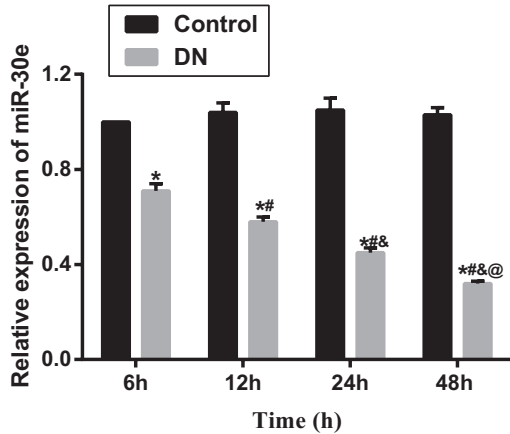

Expression of miR-30e in renal tissues and high-glucose-stimulated RTECs. (A) Comparison of miR-30e expression in renal tissues of two groups of mice. (B) Comparison of miR-30e expression in RTECs cultured with high glucose. (C) Comparison of GLIPR-2 expression in renal tissues of two groups of mice. (D) Comparison of GLIPR-2 expression in RTECs cultured with high glucose. In picture $A$ and $C: * P<0.05$ compared with $\mathrm{db} / \mathrm{m}$ mice of the same age; ${ }^{\#}<0.05$ compared with the 4-week-old db/db mice; $\& P<0.05$ compared with 8-week-old db/db mice; ${ }^{\circledR} P<0.05$ compared with 12-week-old $\mathrm{db} / \mathrm{db}$ mice. In picture B and D $* P<0.05$ compared with RTECs of Control group at the same time point; ${ }^{P} P<0.05$ compared with RTECS of DN group cultured in high glucose for $6 \mathrm{~h}$; \& $P<0.05$ compared with RTECs of DN group cultured in high glucose for $12 \mathrm{~h}$; ${ }^{\circledR} P<0.05$ compared with RTECs of DN group cultured in high glucose for $24 \mathrm{~h}$.
Impact of miR-30e on proliferation of high-glucosestimulated RTECs

MTT method was used to measure the proliferation activity of RTECs that were stimulated by high glucose. Under the exposure to high glucose, the cell proliferation of Mock group and NC group decreased gradually with time, and

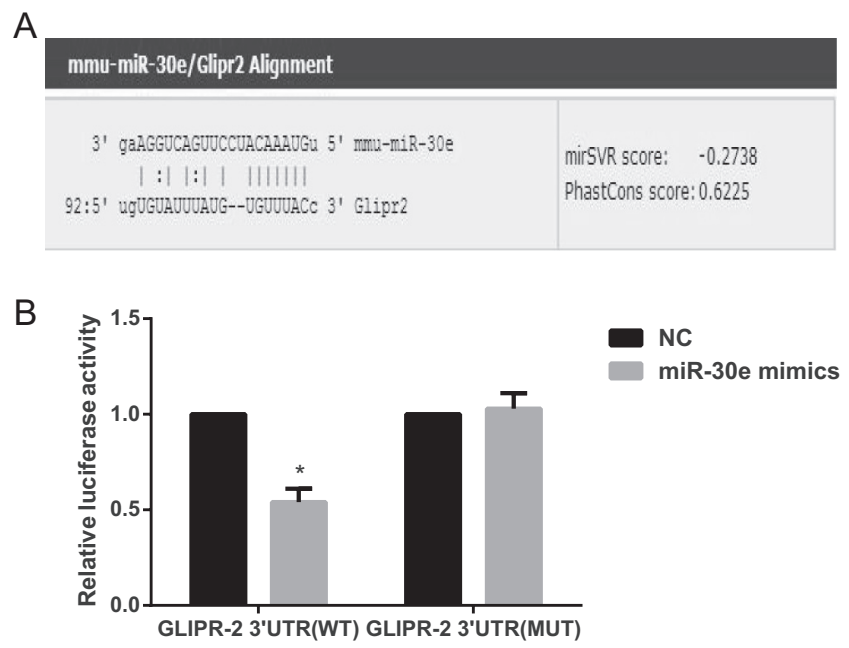

Figure 3

GLIPR-2 is the target gene of miR-30e. (A) The GLIPR-2 3'UTR sequence with miR-30e-binding site presented in microRNA.org. (B) Results of dual-luciferase report gene assay. ${ }^{*} P<0.05$ in comparison with the other three groups.

$\begin{array}{lr}\text { http://jme.endocrinology-journals.org } & \text { ○ } 2017 \text { Society for Endocrinology } \\ \text { DOI: } 10.1530 / J M E-17-0083 & \text { Printed in Great Britain }\end{array}$

no significant difference was observed between the two groups (both $P>0.05$ ). Compared with Mock group and NC group, upregulating the expression of miR-30e and transfecting with si-GLIPR-2 can significantly promote the proliferation of high-glucose-exposed RTECs, but

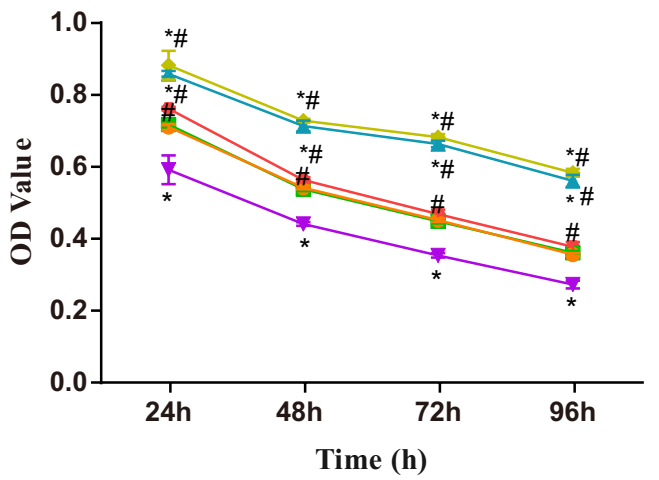

\begin{tabular}{ll|}
$\rightarrow-$ miR-30e inhibitor+si-GLIPR-2 & - miR-30e mimics \\
$-\rightarrow$ si-GLIPR-2 & - NC \\
$\rightarrow$ miR-30e inhibitors & -- Mock
\end{tabular}

Figure 4

Proliferation of high-glucose-exposed RTECs in different transfected groups. Upregulation of miR-30e and transfection with si-GLIPR-2 can significantly promote the proliferation of high-glucose-exposed RTECs, but downregulation of miR-30e can lead to a complete opposite result. $* P<0.05$ compared with RTECs in Mock group at the same time point; $\# P<0.05$ compared with RTECs in miR-30e inhibitor group at the same time point.

Published by Bioscientifica Ltd. 
downregulating miR-30e expression can lead to a complete opposite result (all $P<0.05$ ). In comparison with the miR-30e inhibitor group, miR-30e inhibitor+si-GLIPR-2 group was significantly elevated in proliferation of RTECs $(P<0.05)$ (Fig. 4).

\section{Impact of miR-30e on apoptosis of high-glucose- stimulated RTECs}

Flow cytometry was performed to evaluate the effect of miR-30e on apoptosis rate of high-glucose-stimulated RTECs. As demonstrated in Fig. 5, no evident cell apoptosis was found in Mock and NC groups $(P>0.05)$. There was an obvious reduction of the apoptosis rate of RTECs in miR-30e mimic group and si-GLIPR-2 group, but a marked elevation in miR-30e inhibitor group when compared to Mock group and NC group (all $P<0.05$ ). Furthermore, the apoptosis rate of RTECs in miR-30e inhibitor + si-GLIPR-2 group was significantly lower than in miR-30e inhibitor

\section{Expression of GLIPR-2 and EMT-related factors}

The results of qRT-PCR and Western blot were shown in Fig. 6. In comparison with the Mock group and NC group, miR-30e mimic group and si-GLIPR-2 group were markedly decreased in the gene and protein expression of GLIPR-2, Vimentin, $\alpha$-SMA, Col-I and FN, but apparently increased in the gene and protein expression of $\mathrm{E}$-cadherin (all $P<0.05$ ); however, the results in the miR-30e inhibitor group were completely in the opposite direction (all $P<0.05)$. In addition, when compared with the miR-30e inhibitor group, miR-30e inhibitor+si-GLIPR-2 group showed significant downregulation in the gene and protein expression of GLIPR-2, Vimentin, $\alpha$-SMA, Col-I and $\mathrm{FN}$, but obvious upregulation in the gene and protein expression of E-cadherin (all $P<0.05$ ).

\section{Discussion}

In this study, we applied the $\mathrm{db} / \mathrm{db}$ mouse, which is an animal model, used internationally for DN study due to the extremely similarities to the human patients, with many features such as high blood glucose, high blood lipids and insulin resistance (Sharma et al. 2003). In consistent with a previous report, with the increase of age, db/db mice had significant increase in blood glucose, Scr, BUN and UAE and the morphological observation of renal tissues showed DN pathological changes, such as disordered arrangement of endothelial cells, glomerular hypertrophy and mesangial matrix increase (Tesch \& Lim 2011).

Firstly, we found that, with the increase of mice's age and the prolongation of high-glucose stimulation, the miR-30e expression was downregulated while GLIPR-2 expression was upregulated in a time-dependent fashion. A previous study showed that miRNA can negatively regulate the expression of target gene at the post-transcriptional

A

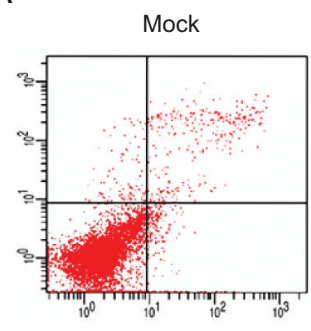

miR-30e inhibitor

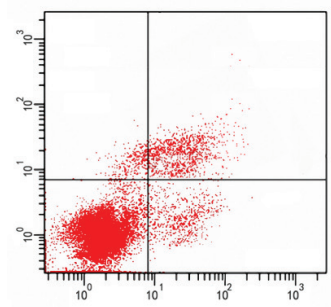

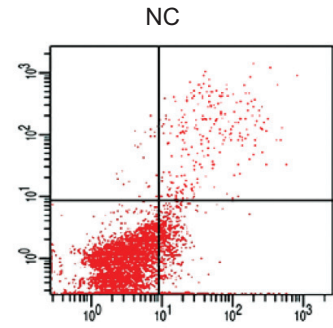

si-GLIPR-2

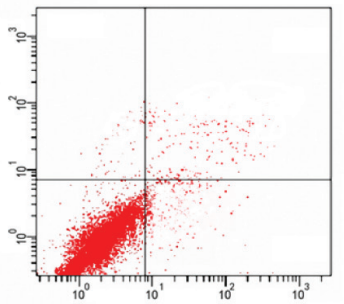

miR-30e mimic

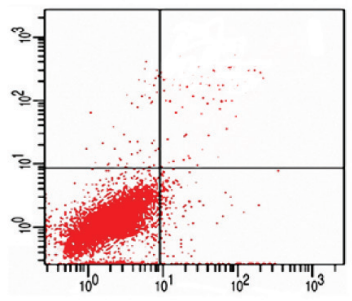

miR-30e inhibitor+si-GLIPR-2

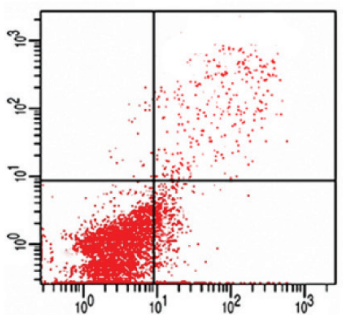

B

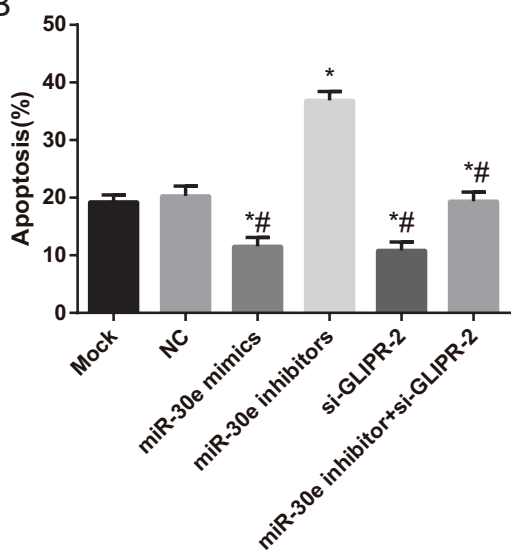

Figure 5

Apoptosis of high-glucose-exposed RTECs in different transfected groups. (A) Flow cytometry was performed to evaluate the effect of miR-30e on apoptosis rate of high-glucose-stimulated RTECs. (B) Comparison of the apoptosis rate of high-glucose-stimulated RTECs in each transfected group. * $P<0.05$ compared with RTECs in Mock group; ${ }^{P}<0.05$ compared with RTECs in miR-30e inhibitor group.

http://jme.endocrinology-journals.org DOI: 10.1530/JME-17-0083
C 2017 Society for Endocrinology Printed in Great Britain
Published by Bioscientifica Ltd 
A

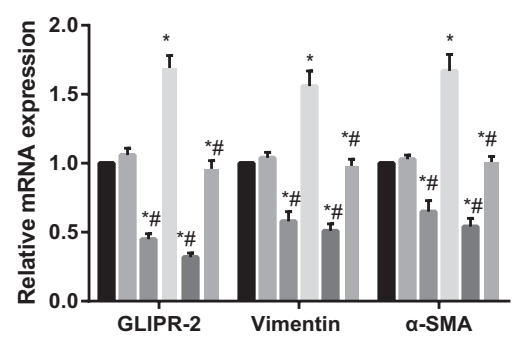

D

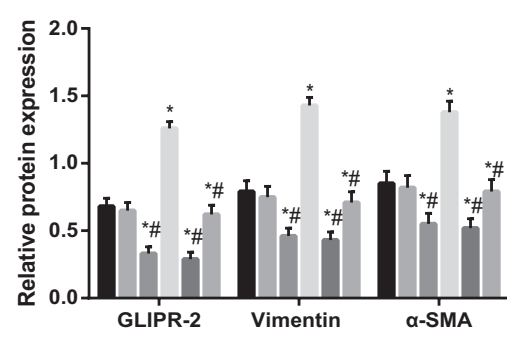

B

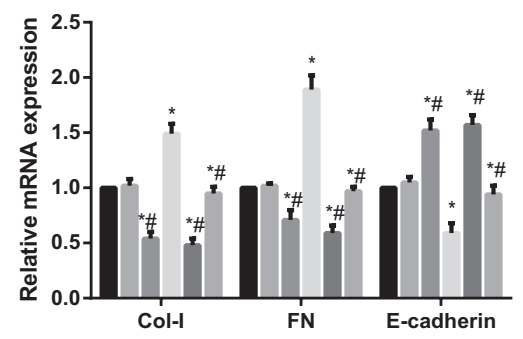

E

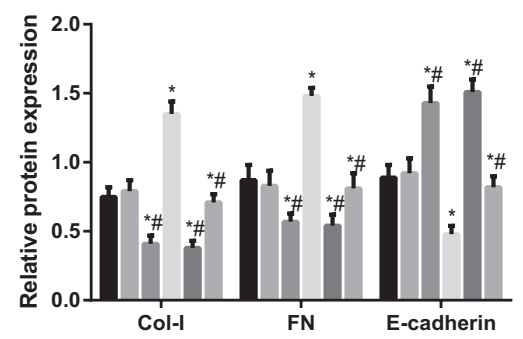

C

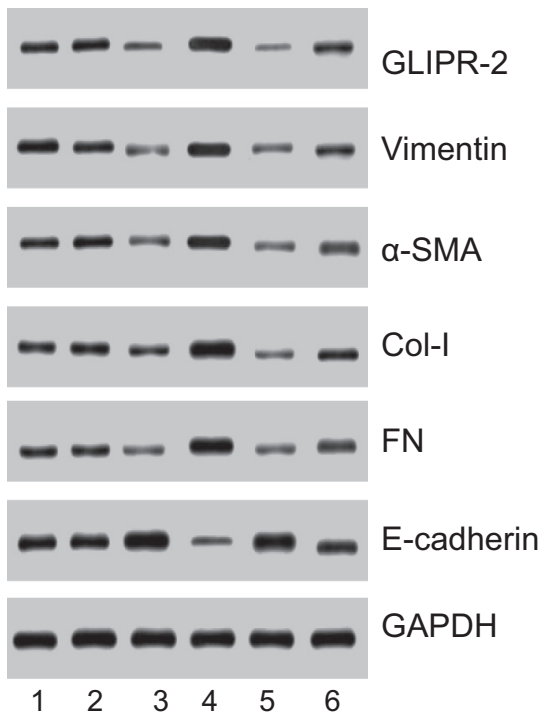

\begin{tabular}{|l|l|}
\hline Mock & miR-30e inhibitors \\
NC & si-GLIPR-2 \\
miR-30e mimics & miR-30e inhibitor+si-GLIPR-2 \\
\hline
\end{tabular}

Figure 6

qRT-PCR and Western blot detect the mRNA and protein expressions of RTECs in each group. (A and B) The mRNA levels of GLIPR-2 and EMT-related factors of cells in each group (qRT-PCR); (C) protein expression of GLIPR-2 and EMT-related factors of cells in each group (Western blot); 1 : Mock group; 2: NC group; 3: miR-30e mimics group; 4: miR-30e inhibitors group; 5: si-GLIPR-2 group; 6: miR-30e inhibitor +si-GLIPR-2 group; (D, E) protein expression levels of GLIPR-2 and EMT-related factors in cells of each group. ${ }^{*} P<0.05$ compared with RTECs in Mock group; ${ }^{*}<0.05$ compared with RTECs in miR-30e inhibitor group.

level through base pairing with the 3'UTR region of target genes (Kaucsar et al. 2010). The luciferase reporter assay in our study further confirmed that GLIPR-2 is the target gene of miR-30e. Additionally, previous studies also found that miR-30 was downexpressed in many diseases, including breast cancer (Yu et al. 2010), myocardial hypertrophy (Chen et al. 2014) and liver fibrosis (Roy et al. 2015). As shown by Duisters RF's group, miR-30 was downexpressed in myocardial fibrosis by targeting a series of ECM mRNA, playing crucial roles in the structural changes of ECM in myocardium (Duisters et al. 2009). Moreover, miR-30 expression was also decreased in prostate cancer specimens, but the overexpression of miR-30 in prostate cancer cells can inhibit EMT phenotype so as to control the cell migration and invasion (Kao et al. 2014). Furthermore, GLIPR-2 was highly expressed in hepatocellular carcinoma cells and overexpressed GLIPR-2 may enhance cell migration and invasion by promoting EMT (Huang et al. $2013 b$ ). Huang and coworkers revealed that GLIPR-2 was upregulated in RTECs of TIF and overexpressed GLIPR-2 promoted the EMT of HK-2 cells by regulating ERK1/2 signaling pathway (Huang et al. 2013a). Besides, Baxter RM also confirmed that expression of GLIPR-2 in kidney might contribute to the progression of fibrosis by increasing the pool of activated fibroblasts (Baxter et al. 2007). Therefore, we hypothesized that miR-30e would decrease in the progression of $\mathrm{DN}$ by negative regulation of GLIPR-2, which may affect the development of TIF, possibly through the induction of EMT.

In addition, EMT in renal epithelial cells is an important mechanism for renal fibrosis (Zeisberg \& Kalluri 2004). Many factors including inflammation and oxidative stress, high glucose, activation of RASS system and TGF- 1 1, may induce EMT in renal epithelial cells, and eventually renal fibrosis (Hills \& Squires 2011, Louis $\&$ Hertig 2015). To our knowledge, E-cadherin, Vimentin and $\alpha$-SMA are most commonly used biomarkers to indicate the occurrence of EMT. For example, E-cadherin is a special adhesion molecule protein, which is of critical significance in maintaining the structural and functional integrity of RTECs (Galichon \& Hertig 2011). Specifically, the loss of E-cadherin would damage the structural integrity of RTECs, activated the interstitial cell phenotype (Vimentin) and followed by the re-structuring from actin cytoskeleton to stress fibers. Then, epithelial cells change from cobblestone shape to long fusiform shape,

Published by Bioscientifica Ltd 
accompanied by the expression of $\alpha$-SMA (Sam et al. 2006, Lamouille et al. 2014). In addition, fibronectin (FN) and collagen I are commonly recognized as the major ECM components (Hu et al. 2015), which were increased with the accumulation of interstitial ECM and the damage of GBM, resulting in the progression of DN (Eberle et al. 2002). A study supported that miR-30 family can target the mRNA of mesenchymal Vimentin to inhibit its translation; the removal of miR-30 by anti-miRNA can lead to mesenchymal phenotype transformation in epithelial cells while the overexpression of miR-30 can maintain the phenotype of epithelial cells (Joglekar et al. 2009a). In addition, transfecting mouse hepatocytes with miR-30 could specifically target Snail1 to significantly inhibit TGF- $\beta 1$-induced EMT (Jingcheng et al. 2012). Our results showed that GLIPR-2 is the target gene of miR-30e; upregulation of miR-30e and transfection with si-GLIPR-2 can reduce the expression of GLIPR-2, Vimentin, $\alpha$-SMA, Col-I and FN in high-glucose-exposed RTECs and enhance the expression of E-cadherin; and the results were in the opposite direction when miR-30e was downregulated. Our finding indicated that miR-30 can reduce the proliferation of mesangial matrix and the deposition of ECM by target inhibition of GLIPR-2, thereby inhibiting the occurrence of GS and TIF in DN patients.

Furthermore, according to our results, the upregulation of miR-30e and the transfection with si-GLIPR-2 can significantly increase the proliferation activity of RTECs, while reduced expression of miR-30e will decrease their proliferative activity. It has been proved that the apoptosis and hypertrophy of renal tubular cells, the damage of GBM and the accumulation of ECM could all lead to high-glucose-induced cell injury (Butcher et al. 1990). Shi and coworkers demonstrated that overexpressed miR-30d can significantly inhibit the expression of TGF- $\beta$-induced caspase- 3 and the apoptosis of podocytes (Shi et al. 2013) and transfected with exogenous miR-30 can significantly improve cytoskeleton damage and apoptosis of podocytes by $\mathrm{Wu}$ (Wu et al. 2013). Above all, miR-30e may activate the downstream signaling pathway by binding with GLIPR-2 in RTECs, which can alleviate the cell damage caused by high-glucose-induced ECM accumulation and inflammatory reactions.

In summary, miR-30e can reduce the occurrence of high-glucose-induced EMT in RTECs by targeting GLIPR-2, possibly because of inhibiting the expression of Vimentin, $\alpha$ SMA, Col-I and FN, and improving the protein expression of E-cadherin. Hence, this study provides a new perspective for the treatment of DN and miR-30e is likely to become a new therapeutic target for the treatment of fibrosis in DN patients.
Declaration of interest

All authors declare no financial conflict of interest with the submission of this manuscript. All authors declare no conflict of interest.

\section{Funding}

This work did not receive any specific grant from any funding agency in the public, commercial, or not-for-profit sector.

\section{Acknowledgments}

The authors would like to give our sincere appreciation to the reviewers for their helpful comments on this article.

\section{References}

Baxter RM, Crowell TP, George JA, Getman ME \& Gardner H 2007 The plant pathogenesis related protein GLIPR-2 is highly expressed in fibrotic kidney and promotes epithelial to mesenchymal transition in vitro. Matrix Biology 26 20-29. (doi:10.1016/j.matbio.2006.09.005)

Brosius FC 3rd, Alpers CE, Bottinger EP, Breyer MD, Coffman TM, Gurley SB, Harris RC, Kakoki M, Kretzler M, Leiter EH, et al. 2009 Mouse models of diabetic nephropathy. Journal of the American Society of Nephrology 20 2503-2512. (doi:10.1681/ASN.2009070721)

Brosius FC, Khoury CC, Buller CL \& Chen S 2010 Abnormalities in signaling pathways in diabetic nephropathy. Expert Review of Endocrinology and Metabolism 5 51-64. (doi:10.1586/eem.09.70)

Butcher GA, Garland T, Ajdukiewicz AB \& Clark IA 1990 Serum tumor necrosis factor associated with malaria in patients in the Solomon Islands. Transactions of the Royal Society of Tropical Medicine and Hygiene 84 658-661. (doi:10.1016/0035-9203(90)90134-Z)

Carbone L 2012 Pain management standards in the eighth edition of the guide for the care and use of laboratory animals. Journal of the American Association for Laboratory Animal Science 51 322-328.

Chen M, Ma G, Yue Y, Wei Y, Li Q, Tong Z, Zhang L, Miao G \& Zhang J 2014 Downregulation of the miR-30 family microRNAs contributes to endoplasmic reticulum stress in cardiac muscle and vascular smooth muscle cells. International Journal of Cardiology 173 65-73. (doi:10.1016/j.ijcard.2014.02.007)

Chung AC 2015 microRNAs in diabetic kidney disease. Advances in Experimental Medicine and Biology 888 253-269. (doi:10.1007/978-3319-22671-2_13)

Duisters RF, Tijsen AJ, Schroen B, Leenders JJ, Lentink V, van der Made I, Herias V, van Leeuwen RE, Schellings MW, Barenbrug P, et al. 2009 miR-133 and miR-30 regulate connective tissue growth factor: implications for a role of microRNAs in myocardial matrix remodeling. Circulation Research 104 170-178. (doi:10.1161/ CIRCRESAHA.108.182535)

Eberle HB, Serrano RL, Fullekrug J, Schlosser A, Lehmann WD, Lottspeich F, Kaloyanova D, Wieland FT \& Helms JB 2002 Identification and characterization of a novel human plant pathogenesis-related protein that localizes to lipid-enriched microdomains in the Golgi complex. Journal of Cell Science $\mathbf{1 1 5}$ 827-838.

Fu Y, Zhang Y, Wang Z, Wang L, Wei X, Zhang B, Wen Z, Fang H Pang Q \& Yi F 2010 Regulation of NADPH oxidase activity is associated with miRNA-25-mediated NOX4 expression in experimental diabetic nephropathy. American Journal of Nephrology 32 581-589. (doi:10.1159/000322105)

Galichon P \& Hertig A 2011 Epithelial to mesenchymal transition as a biomarker in renal fibrosis: are we ready for the bedside? Fibrogenesis and Tissue Repair 4 11. (doi:10.1186/1755-1536-4-11)

Gibbs GM, Roelants K \& O'Bryan MK 2008 The CAP superfamily: cysteine-rich secretory proteins, antigen 5 , and pathogenesis-related

Published by Bioscientifica Ltd. 
1 proteins - roles in reproduction, cancer, and immune defense. Endocrine Reviews 29 865-897. (doi:10.1210/er.2008-0032)

Hills CE \& Squires PE 2011 The role of TGF-beta and epithelial-to mesenchymal transition in diabetic nephropathy. Cytokine and Growth Factor Reviews 22 131-139.

Hu C, Sun L, Xiao L, Han Y, Fu X, Xiong X, Xu X, Liu Y, Yang S, Liu F, et al. 2015 Insights into the mechanisms involved in the expression and regulation of extracellular matrix proteins in diabetic nephropathy. Current Medicinal Chemistry 22 2858-2870. (doi:10.217 4/0929867322666150625095407)

Huang S, Liu F, Niu Q, Li Y, Liu C, Zhang L, Ni D \& Pu X 2013a GLIPR-2 overexpression in HK-2 cells promotes cell EMT and migration through ERK1/2 activation. PLOS ONE 8 e58574. (doi:10.1371/journal.pone.0058574)

Huang SG, Zhang LL, Niu Q, Xiang GM, Liu LL, Jiang DN, Liu F, Li Y \& $\mathrm{Pu}$ X 2013b Hypoxia promotes epithelial-mesenchymal transition of hepatocellular carcinoma cells via inducing GLIPR-2 expression. PLoS ONE 8 e77497. (doi:10.1371/journal.pone.0077497)

Jackson AL \& Levin AA 2012 Developing microRNA therapeutics: approaching the unique complexities. Nucleic Acid Therapeutics 22 213-225.

Jiang L, Qiu W, Zhou Y, Wen P, Fang L, Cao H, Zen K, He W, Zhang C, Dai C, et al. 2013 A microRNA-30e/mitochondrial uncoupling protein 2 axis mediates TGF-beta1-induced tubular epithelial cell extracellular matrix production and kidney fibrosis. Kidney International 84 285-296. (doi:10.1038/ki.2013.80)

Jingcheng Z, Haiyan Z, Junyu L, Xiaolong T, Yuhui Z, Jie Z, Jiangning C, Lei D \& Junfeng Z 2012 miR-30 inhibits TGF- $\beta 1$-induced epithelialto-mesenchymal transition in hepatocyte by targeting Snail1. Biochemical and Biophysical Research Communications 417 1100-1105. (doi:10.1016/j.bbrc.2011.12.121)

Joglekar MV, Patil D, Joglekar VM, Rao GV, Reddy DN, Mitnala S, Shouche Y \& Hardikar AA 2009a The miR-30 family microRNAs confer epithelial phenotype to human pancreatic cells. Islets 1137. (doi:10.4161/isl.1.2.9578)

Joglekar MV, Patil D, Joglekar VM, Rao GV, Reddy DN, Mitnala S, Shouche Y \& Hardikar AA 2009b The miR-30 family microRNAs confer epithelial phenotype to human pancreatic cells. Islets $\mathbf{1}$ 137-147. (doi:10.4161/isl.1.2.9578)

Kainz A, Hronsky M, Stel VS, Jager KJ, Geroldinger A, Dunkler D, Heinze G, Tripepi G \& Oberbauer R 2015 Prediction of prevalence of chronic kidney disease in diabetic patients in countries of the European Union up to 2025. Nephrology Dialysis Transplantation 30 Suppl 4 iv113-118. (doi:10.1093/ndt/gfv073)

Kao CJ, Martiniez A, Shi XB, Yang J, Evans CP, Dobi A, deVere White RW \& Kung HJ 2014 miR-30 as a tumor suppressor connects EGF/Src signal to ERG and EMT. Oncogene 33 2495-2503. (doi:10.1038/onc.2013.200)

Kato M \& Natarajan R 2012 MicroRNA circuits in transforming growth factor-beta actions and diabetic nephropathy. Seminars in Nephrology 32 253-260. (doi:10.1016/j.semnephrol.2012.04.004)

Kato M, Wang L, Putta S, Wang M, Yuan H, Sun G, Lanting L, Todorov I, Rossi JJ \& Natarajan R 2010 Post-transcriptional up-regulation of Tsc-22 by Ybx1, a target of miR-216a, mediates TGF-\{beta\}-induced collagen expression in kidney cells. Journal of Biological Chemistry 285 34004-34015. (doi:10.1074/jbc.M110.165027)

Kaucsar T, Racz Z \& Hamar P 2010 Post-transcriptional gene-expression regulation by micro RNA (miRNA) network in renal disease. Advanced Drug Delivery Reviews 62 1390-1401. (doi:10.1016/j.addr.2010.10.003)

Lamouille S, Xu J \& Derynck R 2014 Molecular mechanisms of epithelial-mesenchymal transition. Nature Reviews Molecular Cell Biology 15 178-196. (doi:10.1038/nrm3758)
Long J, Wang Y, Wang W, Chang BH \& Danesh FR 2011 MicroRNA-29c is a signature microRNA under high glucose conditions that targets Sprouty homolog 1 , and its in vivo knockdown prevents progression of diabetic nephropathy. Journal of Biological Chemistry 286 11837-11848. (doi:10.1074/jbc.M110.194969)

Louis K \& Hertig A 2015 How tubular epithelial cells dictate the rate of renal fibrogenesis? World Journal of Nephrology 4 367-373. (doi:10.5527/wjn.v4.i3.367)

Marshall SM 2014 Natural history and clinical characteristics of CKD in type 1 and type 2 diabetes mellitus. Advances in Chronic Kidney Disease 21 267-272. (doi:10.1053/j.ackd.2014.03.007)

Roy S, Benz F, Vargas Cardenas D, Vucur M, Gautheron J, Schneider A, Hellerbrand C, Pottier N, Alder J, Tacke F, et al. 2015 miR-30c and miR-193 are a part of the TGF-beta-dependent regulatory network controlling extracellular matrix genes in liver fibrosis. Journal of Digestive Diseases 16 513-524. (doi:10.1111/1751-2980.12266)

Sam R, Wanna L, Gudehithlu KP, Garber SL, Dunea G, Arruda JA \& Singh AK 2006 Glomerular epithelial cells transform to myofibroblasts: early but not late removal of TGF-beta1 reverses transformation. Translational Research 148 142-148. (doi:10.1016/j.trsl.2006.04.003)

Sharma K, McCue P \& Dunn SR 2003 Diabetic kidney disease in the $\mathrm{db} / \mathrm{db}$ mouse. American Journal of Physiology: Renal Physiology $\mathbf{2 8 4}$ F1138-1144.

Shi S, Yu L, Zhang T, Qi H, Xavier S, Ju W \& Bottinger E 2013 Smad2dependent downregulation of miR-30 is required for TGF- $\beta$-induced apoptosis in podocytes. PLOS ONE 8 e75572. (doi:10.1371/journal. pone.0075572)

Shields J \& Maxwell AP 2010 Managing diabetic nephropathy. Clinical Medicine 10 500-504. (doi:10.7861/clinmedicine.10-5-500)

Simpson K, Wonnacott A, Fraser DJ \& Bowen T 2016 MicroRNAs in diabetic nephropathy: from biomarkers to therapy. Current Diabetes Reports 16 35. (doi:10.1007/s11892-016-0724-8)

Tesch GH \& Lim AK 2011 Recent insights into diabetic renal injury from the $\mathrm{db} / \mathrm{db}$ mouse model of type 2 diabetic nephropathy. American Journal of Physiology: Renal Physiology 300 F301-F310. (doi:10.1152/ajprenal.00607.2010)

Wang B, Koh P, Winbanks C, Coughlan MT, McClelland A, Watson A, Jandeleit-Dahm K, Burns WC, Thomas MC, Cooper ME, et al. 2011 miR-200a Prevents renal fibrogenesis through repression of TGFbeta2 expression. Diabetes 60 280-287. (doi:10.2337/db10-0892)

Wu J, Zheng C, Fan Y, Zeng C, Chen Z, Qin W, Zhang C, Zhang W, Wang X \& Zhu X 2013 Downregulation of microRNA-30 facilitates podocyte injury and is prevented by glucocorticoids. Journal of the American Society of Nephrology 25 92-104. (doi:10.1681/ASN.2012111101)

Wu L, Wang Q, Guo F, Ma X, Ji H, Liu F, Zhao Y \& Qin G 2016 MicroRNA27 a induces mesangial cell injury by targeting of PPARgamma, and its in vivo knockdown prevents progression of diabetic nephropathy. Scientific Reports 6 26072. (doi:10.1038/srep26072)

Yu F, Deng H, Yao H, Liu Q, Su F \& Song E 2010 Mir-30 reduction maintains self-renewal and inhibits apoptosis in breast tumorinitiating cells. Oncogene 29 4194-4204. (doi:10.1038/onc.2010.167)

Zeisberg M \& Kalluri R 2004 The role of epithelial-to-mesenchymal transition in renal fibrosis. Journal of Molecular Medicine 82 175-181. (doi:10.1007/s00109-003-0517-9)

Zhang J, Li S, Li L, Li M, Guo C, Yao J \& Mi S 2015 Exosome and exosomal microRNA: trafficking, sorting, and function. Genomics, Proteomics and Bioinformatics 13 17-24. (doi:10.1016/j.gpb.2015.02.001)

Zheng Z, Guan M, Jia Y, Wang D, Pang R, Lv F, Xiao Z, Wang L, Zhang H \& Xue Y 2016 The coordinated roles of miR-26a and miR-30c in regulating TGFbeta1-induced epithelial-to-mesenchymal transition in diabetic nephropathy. Scientific Reports 6 37492. (doi:10.1038/srep37492)

Received in final form 2 June 2017

Accepted 13 June 2017

Accepted Preprint published online 13 June 2017 http://jme.endocrinology-journals.org

DOI: 10.1530/JME-17-0083
() 2017 Society for Endocrinology Printed in Great Britain
Published by Bioscientifica Ltd 